\title{
Concept acquisition as a function of frequency of occurrence in verbal context
}

SANDRA J. WOOLUM and DONALD M. JOHNSON, Michigan State University, East Lansing, Mich. 48823

The experiment investigated concept acquisition as a function of number of occurrences of an unknown word in the context of a short story. Each of the nine stories was presented in one of six conditions $(0,1,2,4,8,12$ occurrences of the word) to 120 college students. Five-item multiple-choice tests constructed to test concept acquisition showed adequate reliability, and for each word improvement was significant at the .01 level. Hence the learning of concepts from verbal context can be studied systematically, and the improvement, as in other learning experiments, appears to be a decreasing function of practice.

Most laboratory experiments on concept learning require $\mathrm{S}$ to classify objects and attach an artificial label, such as dax, to the class, and many writers seem to assume that this procedure is typical of concept learning in general. Others, notably Carroll (1964), have pointed out that the reverse sequence is also common; a child hears a word-not an artificial word like dax but a standard word like uncle or temperature-and then learns the class or the dimension to which it refers. Theoretical accounts of how a concept may be acquired from the context of a verbal communication have been offered (Mowrer, 1954; Staats, 1968), but experimental investigations are few. Werner \& Kaplan (1950) discovered a developmental trend in children's ability to abstract the meaning of a word from one sentence and apply it to another sentence. Johnson \& Stratton (1966) found that learning concepts from verbal context was not inferior to learning from definitions, from synonyms, or by practice in classification, and that transfer from one method to another was practically complete.

In a systematic investigation of this kind of learning the basic variable to be examined first is frequency of presentation. From the results of more familiar learning experiments it is reasonable to expect that concept acquisition in this situation will be a decreasing function of frequency: For want of a more standard unit, the reading of a sentence containing the concept was taken as the unit of practice.

METHOD

Nine words were randomly chosen from the Thorndike \& Lorge (1944) list of words that occur four times per 18 million: AMERCE, CANARD, DIZEN, MARMOREAL, PHARISAICAL, POSSET, PURSY, SAPONIFY, and TUSAH.
A story which used the word once in each of 12 sentences was written for each word, with a clue to the meaning of the concept in each sentence. Each story was used in its complete form and in condensed forms that contained $1,2,4$, or 8 of the 12 sentences. With the inclusion of a zero presentation there were thus six presentation conditions for each word. The following is the complete version for MARMOREAL.

The marmoreal snow stretched endlessly over the plains. In the midst of the snow, an artist was trying to capture the marmoreal quality on canvas. The marmoreal snow was a perfect study because it was cold and white. The marmoreal quality, however, was almost impossible to capture in all its smoothness. Finally the artist began to capture the fine marmoreal quality with his brush. He was ecstatic to think how his marmoreal snow resembled the marble columns of more classic painters. He said to himself, "I will call the painting, 'The marmoreal snow,' and it will make me famous." But long did the marmoreal painting hang in the store without being bought though everyone admitted that its texture and icy effect were beautiful. No one wanted a marmoreal painting because it was all white. One day an important museum curator saw 'The marmoreal snow,' and asked who had painted it. Unfortunately, no one knew who had painted the smooth, white marmoreal work. The artist had loved its marmoreal quality too much to mar it by signing his name.

Five multiple-choice questions were written to test acquisition of the meaning of each new word. The following is a sample question for MARMOREAL. There is probably nothing marmoreal: (a) in the modern city; (b) on a hot summer day; (c) in a museum; (d) in the jungle; and (e) on a cold winter night.

Each $S$ received each of the nine stories in one of the six conditions. Eighteen ways of combining stories and conditions were randomly chosen with the stipulation that each story occur once and only once, that each condition occur once, and that no condition occur more than twice. Each selection was printed on a single page (with a blank page for the zero condition) and followed by a page of five relevant questions. The stories were randomly ordered and stapled in booklets.

The booklets were distributed to an experimental psychology class of 120 students, hence there were 20 Ss in each condition for each of the nine stories. The students were instructed to read each story to discover the meaning of the new words and then to attempt to answer all test questions.

Table 1

A Achievement Data for Nine Concepts Learned from the Context of 0-12 Sentences

\begin{tabular}{|c|c|c|c|c|c|c|c|c|}
\hline \multirow[b]{2}{*}{ Word } & & \multicolumn{6}{|c|}{ Mean Score for Each Condition } & \multirow[b]{2}{*}{$\mathbf{F}$} \\
\hline & \multicolumn{2}{|c|}{ Reliability 0} & 1 & 2 & 4 & 8 & 12 & \\
\hline Amerce & .72 & 1.30 & 1.80 & $4.55^{*}$ & $3.95^{*}$ & $4.05^{*}$ & 4.60 & $13.9 * *$ \\
\hline Canard & .19 & 1.60 & 1.25 & $2.45^{*}$ & 1.35 & 1.60 & 1.75 & $3.6^{* *}$ \\
\hline Dizen & .42 & 2.05 & 1.45 & 2.15 & 2.65 & $3.00^{*}$ & $3.40^{*}$ & $5.3 * *$ \\
\hline Marmoreal & .60 & 2.05 & $3.85^{*}$ & 2.00 & 2.40 & $2.95^{*}$ & $3.15^{*}$ & $6.5 * *$ \\
\hline Pharisaical & .74 & 1.85 & $3.20^{*}$ & $3.00^{*}$ & $3.50^{*}$ & $4.05^{*}$ & $4.00^{*}$ & $7.7 * *$ \\
\hline Posset & .59 & 2.00 & 2.05 & 2.55 & 2.35 & $3.20^{*}$ & $4.05 *$ & $8.9^{* *}$ \\
\hline Pursy & .69 & 1.95 & .75 & 2.85 & 1.55 & $3.20^{*}$ & $2.95^{*}$ & $8.4^{* *}$ \\
\hline Saponify & .71 & 1.75 & $2.95^{*}$ & $3.45^{*}$ & $4.40^{*}$ & $4.25 *$ & $4.50^{*}$ & $21.0 * *$ \\
\hline Tussah & .71 & .85 & 1.50 & $2.70^{*}$ & $3.60^{*}$ & $4.00^{*}$ & $3.80^{*}$ & $17.1 * *$ \\
\hline Total & & 1.70 & 2.09 & 2.86 & 2.86 & 3.37 & 3.58 & \\
\hline Subtotal & & 1.54 & 2.30 & 3.01 & 3.11 & 3.67 & 3.86 & \\
\hline
\end{tabular}

* $p<.05$, mean $>$ mean for zero condition at .05 level.

** $p<.01$. 
They worked at their own speed, but most finished in about $30 \mathrm{~min}$.

\section{RESULTS}

The reliability of the test of achievement of each concept, computed by the Kuder-Richardson method (No. 20), is shown in Table 1. With the exception of CANARD and perhaps DIZEN they are adequate for present purposes.

Mean scores for the six conditions for each word are given in Table 1. Analysis of variance showed a significant $F$ at the .01 level between conditions for each word, and the mean for the 12-sentence condition was higher than the mean for the zero condition in every case. Obviously the Ss learned something of the meaning of these difficult concepts in a few minutes, and the mean for a few words approached the maximum score of five.

The rates of learning were quite irregular, however. Duncan's range tests performed on the six conditions for each word indicate that the significant differences were inconsistent. For example, the one-sentence condition for MARMOREAL was significantly different from all other conditions except the 12-sentence condition. Any generalization about the shape of the learning curve under these conditions is questionable, but the bottom line in Table 1, from which the relatively unreliable data of CANARD and DIZEN have been omitted, gives a reasonable first approximation.

\section{DISCUSSION}

The variations in the results for the different words are probably due to the difficulty of writing twelve equally valuable sentences. It is possible also that the test items were more relevant to some sentences than others. The results obtained when these variations are smoothed by summing across words suggest that rate of learning words in the context of sentences is a decreasing function not unlike learning curves obtained in more conventional experiments.

Methodologically, this experiment demonstrates that systematic study of concept learning through context is possible and that under present conditions the learning proceeds quite rapidly. The data at hand suggest that eight sentences would be sufficient for comparisons between different materials and different conditions. Further work directed toward the specific contribution of each sentence to the acquisition of meaning is in progress.

\section{REFERENCES}

CARROLL, J. B. Words, meanings and concepts. Harvard Educational Review, 1964, 34, 178-202.

JOHNSON, D. M., \& STRATTON, R. P. Evaluation of five methods of teaching concepts. Joumal of Educational Psychology, 1966, 57, 48-53.

MOWRER, H. O. The psychologist looks at language. American Psychologist, 1954, 9, 660-694.

STAATS, A. W. Learning, language and cognition. New York: Holt, Rinehart, \& Winston, 1968.

THORNDIKE, E. L., \& LORGE, I. The teacher's word book of 30,000 words. New York: Columbia University Publications, 1944.

WERNER, H., \& KAPLAN, E. The acquisition of word meanings. Monograph of the Society for Research in Child Development, 1950, $15,3-120$.

\section{Comment on Schurman: Effects of an artificial pupil in visual perception'}

\section{R. HILZ and C. R. CAVONIUS, The Eye Research Foundation, Bethesda, Md. $20014^{2}$}

Schurman's equipment did not include an artificial pupil, and his results cannot be interpreted as evidence supporting the use of an artificial pupil in visual research.

Schurman (1968) reported an experiment which purports to demonstrate the effect of an artificial pupil on visual perception. Unfortunately, this study is based on an unconventional concept of the nature of an artificial pupil. An artificial pupil by definition replaces the natural pupil as the aperture stop for the eye, whereas Schurman's diaphragm, because of its size and distance from the $O$, acts as a field stop. This failure to distinguish between the functions of field and aperture stops results in several incorrect statements about an artificial pupil. An artificial pupil does not "limit the amount of retina illuminated" because (like a camera diaphragm) it is located in a plane which is not imaged on the retina. It does not "eliminate stray and scattered light from a point source" (whatever that may be), nor does it act as a "lens of infinite focal length and zero curvature," which of course is no lens at all.

In order to be effective, an artificial pupil should be located in, or close to, the plane of the natural pupil, and must be smaller than the natural pupil. Schurman's diaphragm, on the other hand, was located 8 in. from the eye, and was substantially larger than either the natural pupil or the largest dimension of the stimulus pattern. Therefore, this diaphragm cannot intercept any part of the light from the stimulus pattern which reaches the eye. In short, Schurman's explanation of his experimental results is almost certainly incorrect. Without further information about his apparatus or the variance of his data, we can only speculate that his field stop improved contrast by reducing stray light from sources other than his stimuli.

Schurman is correct in stating that an artificial pupil increases the depth of field. However, artificial pupils smaller than about $1.5 \mathrm{~mm}$ degrade the retinal image by increasing the effects of diffraction. When working at low luminance levels, any artificial pupil may degrade performance by reducing retinal illumination. An artificial pupil may also distort the perceived size of stimuli, due to accommodative effects (Biersdorf \& Baird, 1966).

It is probably not feasible to set down definite rules for the use of artificial pupils, since the best pupil size will depend on parameters such as luminance level, accommodation, and visual task. Diameters of about $3 \mathrm{~mm}$ are commonly found to be optimal (Riggs, 1965). The artificial pupil should be located near the eye or be optically placed in the plane of the natural pupil, as in Maxwellian view. While a field stop may improve visual performance in some cases (as it seems to have done for Schurman), it does not increase the depth of field nor reduce the aberrations of the eye.

\section{REFERENCES}

BIERSDORF, W. R., \& BAIRD, J. C. Effects of an artificial pupil and accommodation on retinal image size. Journal of the Optical Society of America, 1966, 56, 1123-1129.

RJGGS, L. A. Visual Acuity. In C. H. Graham (Ed.), Vision and visual perception. New York: Wiley, 1965. P. 334.

SCHURMAN, D. L. Effects of an artificial pupil in visual perception. Psychonomic Science, 1968, 11, 57.

$$
\text { NOTES }
$$

1. Supported by NSF Grant GB -4260 .

2. An affiliate of the University of Maryland. 